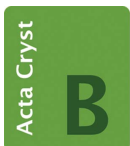

STRUCTURAL SCIENCE CRYSTAL ENGINEERING MATERIALS

ISSN 2052-5206

Received 1 April 2021

Accepted 19 June 2021

Edited by J. Lipkowski, Polish Academy of Sciences, Poland

Keywords: tribromobenzene isomers; structureproperty relationship; melting point; molecular symmetry; noncovalent interactions; halogen bond.

CCDC references: 2041515; 2041516; 2041517; 2041518; 2041519; 2041520; $2041521 ; 2041522 ; 2041523$

Supporting information: this article has supporting information at journals.iucr.org/b

\section{Properties and interactions - melting point of tribromobenzene isomers}

\author{
Maciej Bujak, $^{a *}$ Marcin Podsiadło ${ }^{\mathrm{b}}$ and Andrzej Katrusiak ${ }^{\mathrm{b} *}$ \\ ${ }^{\mathbf{a}}$ Faculty of Chemistry, University of Opole, Oleska 48, Opole, 45-052, Poland, and ${ }^{\mathbf{b}}$ Faculty of Chemistry, \\ Adam Mickiewicz University, Uniwersytetu Poznańskiego 8, Poznań, 61-614, Poland. *Correspondence e-mail: \\ mbujak@uni.opole.pl,katran@amu.edu.pl
}

Single crystals of isomeric 1,2,3-tribromobenzene (123TBB), 1,2,4-tribromobenzene (124TBB) and 1,3,5-tribromobenzene (135TBB) have been grown from different solvents and their structures determined by X-ray diffraction at 100 , 200 and $270 \mathrm{~K}$. The melting-point differences of $c a 40 \mathrm{~K}$ between 135TBB, $123 \mathrm{TBB}$ and $124 \mathrm{TBB}$ have been correlated with the molecular symmetry and packing preferences in the crystal, as well as with the main types of intermolecular halogen interactions, i.e. $\mathrm{Br} \cdots \mathrm{Br}, \mathrm{Br} \cdots \mathrm{C}(\mathrm{Br} \cdots \pi)$ and $\mathrm{Br} \cdots \mathrm{H}$. The relationship between symmetry and melting point in Carnelley's rule has been extended to the accessibility of terminal atoms for the formation of intermolecular interactions, their occurrences and distribution, and the close packing. The electrostatic potential mapped on molecular surfaces demonstrates that in more symmetric molecules the more evenly distributed substituents are more accessible and form more optimum intermolecular interactions.

\section{Introduction}

Melting point is one of the fundamental thermodynamic parameters that can be quickly and cheaply determined, and used, along with other parameters, to identify a substance, check its purity and characterize its properties. Most physicochemical tables list melting and boiling points, and solubility, along with other parameters of various compounds. These parameters change in a characteristic way for compounds forming a homologous series, for example, analogous derivatives with different substituents. However, the most interesting from a structural point of view are the exceptions and anomalies in the well established trends of these series, and in particular polymorphs and very similar compounds, including isomers.

Numerous studies have been dedicated to the rules and factors affecting the melting point that could be calculated as the quotient of enthalpy and entropy of melting (Carnelley, 1882; Beacall, 1928; Holler, 1948; Gavezzotti, 1995; Brown \& Brown, 2000; Boese et al., 1999; Thalladi \& Boese, 2000; Thalladi et al., 2000a,b,c; Katritzky et al., 2001; Bujak et al., 2008; Joseph et al., 2011; Podsiadło et al., 2012, 2013; Yalkowsky \& Alantary, 2018; Gallagher et al., 2019). The studies showed that the location of substituents in molecules and their ability to form intermolecular interactions cannot be neglected when explaining the melting-point differences of isomers. In a recent study on tetrachlorobenzene isomers, both the nature and distribution of interactions were correlated with the melting points of these relatively simple compounds, by representing the molecular symmetry and magnitudes of 
electrostatic potential on the molecular surfaces (Bujak, 2018).

In this article, we continue our studies on the differences in melting points of isomers for tribromobenzenes (Scheme 1 shows the tribromobenzene isomers, their abbreviations, the molecular point-group symmetries and the melting points). We have determined the crystal structures at 270, 200 and $100 \mathrm{~K}$. The experimental study is supported by a Hirshfeld surface analysis and quantum-chemical calculations. We were particularly interested in the nature of the intermolecular interactions, their thermal behaviour and the relationships of the various structural parameters to the differences in the melting points of these compounds.<smiles>Brc1cccc(Br)c1Br</smiles>

123TBB

$\mathrm{C}_{2 v}$ $\mathrm{mp}=361.0 \mathrm{~K}$<smiles>Brc1ccc(Br)c(Br)c1</smiles>

124TBB

$C_{s}$ $\mathrm{mp}=317.7 \mathrm{~K}$<smiles>Brc1cc(Br)cc(Br)c1</smiles>

$\mathrm{mp}=396.0 \mathrm{~K}$
All tribromobenzene isomers are solid under ambient conditions, with their melting points above $315 \mathrm{~K}$ (Mackay et al., 2006). As illustrated in Fig. 1, in accordance with the molecular symmetry and Carnelley's rule (Carnelley, 1882; Brown \& Brown, 2000), the highest melting point is that of $135 \mathrm{TBB}\left(396.0 \mathrm{~K}\right.$, molecular symmetry $\left.D_{3 h}\right)$, then lower by $35 \mathrm{~K}$ is that of $123 \mathrm{TBB}\left(361.0 \mathrm{~K} C_{2 v}\right.$ symmetry) and still $43 \mathrm{~K}$ lower is that of $124 \mathrm{TBB}\left(317.7 \mathrm{~K}, C_{s}\right.$ symmetry). These melting-point differences indicate that the structural dissimilarities between the tribromobenzene isomers could be related to their molecular symmetry (i.e. the location of the $\mathrm{Br}$

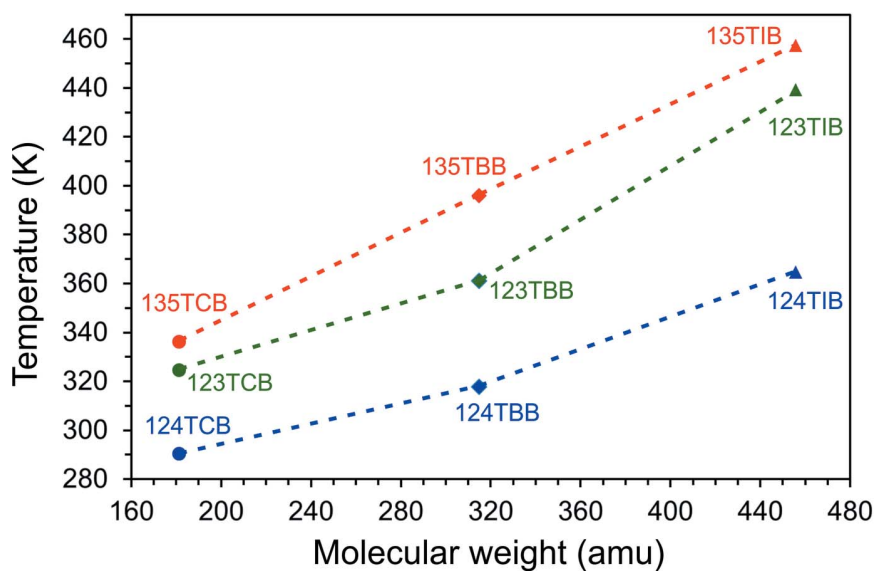

Figure 1

Melting points (Mackay et al., 2006) for series of isomers: $(\bullet)$ trichloro$(\mathrm{TCB}),(\bullet)$ tribromo- (TBB) and ( $\mathbf{\wedge})$ triiodobenzenes (TIB), plotted as a function of their molecular weight. The dashed lines joining the points are guides for the eye only.
Table 1

Selected crystal data for $123 \mathrm{TBB}, 124 \mathrm{TBB}$ and $135 \mathrm{TBB}$ at $100 \mathrm{~K}$.

\begin{tabular}{llll}
\hline & $123 \mathrm{TBB}$ & $124 \mathrm{TBB}$ & $135 \mathrm{TBB}$ \\
\hline Chemical formula & $\mathrm{C}_{6} \mathrm{H}_{3} \mathrm{Br}_{3}$ & $\mathrm{C}_{6} \mathrm{H}_{3} \mathrm{Br}_{3}$ & $\mathrm{C}_{6} \mathrm{H}_{3} \mathrm{Br}_{3}$ \\
$M_{\mathrm{r}}$ & 314.78 & 314.78 & 314.78 \\
Crystal system & Monoclinic & Orthorhombic & Orthorhombic \\
Space group, $Z, Z^{\prime}$ & $P 2_{1} / c, 8,2$ & $F d d 2,48,3$ & $P 2_{1} 2_{1} 2_{1}, 4,1$ \\
$a(\AA)$ & $12.7973(5)$ & $29.313(2)$ & $4.00341(11)$ \\
$b(\AA)$ & $8.2623(3)$ & $78.645(4)$ & $13.4119(3)$ \\
$c(\AA)$ & $15.4666(6)$ & $3.9320(2)$ & $14.0916(4)$ \\
$\beta\left({ }^{\circ}\right)$ & $113.102(5)$ & 90 & 90 \\
$V\left(\AA^{3}\right)$ & $1504.22(11)$ & $9064.5(9)$ & $756.63(3)$ \\
$R\left[F^{2}>2 \sigma\left(F^{2}\right)\right]$ & 0.027 & 0.061 & 0.018 \\
$w R\left(F^{2}\right)$ & 0.055 & 0.135 & 0.036 \\
\hline
\end{tabular}

atoms in the aromatic ring), as well as the distinct molecular interactions and crystal packing preferences.

Of all the tribromobenzenes, so far only the structure of $135 \mathrm{TBB}$ was determined at room temperature (Milledge \& Pant, 1960; Belaaraj et al., 1984). Milledge \& Pant (1960) established that $135 \mathrm{TBB}$ does not undergo any discontinuous phase transition between room and liquid-nitrogen temperature.

\section{Experimental}

Samples of 123TBB (98\%; Tokyo Chemical Industry Co. Ltd), 124TBB and 135TBB (95 and 99\%, respectively; Fluorochem Ltd) were recrystallized from different solvents. The best crystals of $123 \mathrm{TBB}$ and $124 \mathrm{TBB}$ were obtained at room temperature by the slow evaporation from ethanol $(96 \%$, POCH S.A.) solutions, whereas for $135 \mathrm{TCB}$, the tetrachloromethane (EUROCHEM BGD Sp. z o.o.) solution performed better.

Single crystals of the tribromobenzene isomers were selected under a polarizing microscope and sealed in thinwalled glass capillaries (from Hilgenberg $\mathrm{GmbH}$, with an internal diameter of $0.3 \mathrm{~mm}$ and walls $0.01 \mathrm{~mm}$ thick). The samples were cooled in a stream of nitrogen gas from an Oxford Cryosystems attachment. The diffraction data were collected for each crystal first at $270 \mathrm{~K}$ and then at $200 \mathrm{~K}$ and $100 \mathrm{~K}$ on a single-crystal Xcalibur Eos CCD diffractometer with graphite-monochromated Mo $K \alpha$ radiation. Reflections were measured using the $\omega$-scan technique with $\Delta \omega=1.0^{\circ}$ images exposed for 10 (for 123TBB and 135TBB) and $7.5 \mathrm{~s}$ (for 124TBB). CrysAlisPro (Rigaku Oxford Diffraction, 2018) was used for collecting data and data reduction. All data were accounted for Lorentz, polarization and analytical sample absorption effects. The structures were solved by direct methods and refined with SHELX (Sheldrick, 2008, 2015). Noncentrosymmetric $124 \mathrm{TBB}$ and $135 \mathrm{TBB}$ were refined as inversion twins. The $\mathrm{H}$-atom positions in all the structures were located in difference Fourier maps and the riding model was applied. The isotropic displacement parameters of the $\mathrm{H}$ atoms were fixed to $1.2 U_{\text {eq }}$ of their carriers.

Intermolecular contacts were compared using Hirshfeld surface analysis with CrystalExplorer17 (Turner et al., 2017) and the structures were drawn with Mercury (Macrae et al., 
Table 2

Short intermolecular $\mathrm{Br} \cdots \mathrm{Br}$ distances $(\AA)$ and angles $\left({ }^{\circ}\right)$ in 123TBB, $124 \mathrm{TBB}$ and $135 \mathrm{TBB}$ at 270,200 and $100 \mathrm{~K}$.

\begin{tabular}{llll}
\hline & $270 \mathrm{~K}$ & $200 \mathrm{~K}$ & $100 \mathrm{~K}$ \\
\hline $123 \mathrm{TBB}$ & & & \\
$\mathrm{Br} 11 \cdots \mathrm{Br} 12^{\mathrm{i}}$ & $3.6440(10)$ & $3.6175(8)$ & $3.5850(6)$ \\
$\mathrm{C} 11-\mathrm{Br} 11 \cdots \mathrm{Br} 12^{\mathrm{i}}$ & $162.75(19)$ & $162.83(17)$ & $163.37(15)$ \\
$\mathrm{Br} 11 \cdots \mathrm{Br} 12^{\mathrm{i}}-\mathrm{C} 12^{\mathrm{i}}$ & $135.03(16)$ & $135.19(14)$ & $135.10(12)$ \\
& & & \\
$124 \mathrm{TBB}$ & & & \\
$\mathrm{Br} 11 \cdots \mathrm{Br} 34^{\mathrm{ii}}$ & $3.687(4)$ & $3.651(3)$ & $3.606(3)$ \\
$\mathrm{C} 11-\mathrm{Br} 11 \cdots \mathrm{Br} 34^{\mathrm{ii}}$ & $99.2(7)$ & $99.4(6)$ & $99.7(5)$ \\
$\mathrm{Br} 11 \cdots \mathrm{Br} 34^{\mathrm{ii}}-\mathrm{C} 34^{\mathrm{ii}}$ & $171.2(7)$ & $172.6(6)$ & $172.2(6)$ \\
$\mathrm{Br} 14 \cdots \mathrm{Br} 21^{\mathrm{iii}}$ & $3.751(4)$ & $3.722(3)$ & $3.676(3)$ \\
$\mathrm{C} 14-\mathrm{Br} 14 \cdots \mathrm{Br} 21^{\mathrm{iii}}$ & $86.3(6)$ & $86.2(6)$ & $86.0(6)$ \\
$\mathrm{Br} 14 \cdots \mathrm{Br} 21^{\mathrm{iii}}-\mathrm{C} 21^{\mathrm{iii}}$ & $161.4(7)$ & $162.0(6)$ & $162.1(6)$ \\
$\mathrm{Br} 14 \cdots \mathrm{Br} 31$ & $3.698(4)$ & $3.672(3)$ & $3.640(3)$ \\
$\mathrm{C} 14-\mathrm{Br} 14 \cdots \mathrm{Br} 31$ & $165.7(8)$ & $165.2(7)$ & $165.4(6)$ \\
$\mathrm{Br} 14 \cdots \mathrm{Br} 31-\mathrm{C} 31$ & $105.6(7)$ & $105.0(6)$ & $105.5(6)$ \\
$\mathrm{Br} 21 \cdots \mathrm{Br} 24^{\mathrm{iv}}$ & $3.630(4)$ & $3.606(3)$ & $3.565(3)$ \\
$\mathrm{C} 21-\mathrm{Br} 21 \cdots \mathrm{Br} 24^{\mathrm{iv}}$ & $102.7(6)$ & $102.3(6)$ & $103.3(5)$ \\
$\mathrm{Br} 21 \cdots \mathrm{Br} 24^{\mathrm{iv}}-\mathrm{C} 24^{\mathrm{iv}}$ & $174.2(7)$ & $174.9(6)$ & $175.9(6)$ \\
& & & \\
$135 \mathrm{TBB}$ & & & \\
$\mathrm{Br} 13 \cdots \mathrm{Br} 13^{\mathrm{v}}$ & $3.7411(13)$ & $3.7094(9)$ & $3.6724(8)$ \\
$\mathrm{C} 13-\mathrm{Br} 13 \cdots \mathrm{Br} 13^{\mathrm{v}}$ & $151.9(2)$ & $152.15(16)$ & $152.14(15)$ \\
$\mathrm{Br} 13 \cdots \mathrm{Br} 13^{\mathrm{v}}-\mathrm{C} 13^{\mathrm{v}}$ & $112.4(2)$ & $112.16(15)$ & $112.30(14)$ \\
$\mathrm{Br} 13 \cdots \mathrm{Br} 15^{\mathrm{vi}}$ & $3.7458(11)$ & $3.7252(8)$ & $3.6994(7)$ \\
$\mathrm{C} 13-\mathrm{Br} 13 \cdots \mathrm{Br} 15^{\mathrm{vi}}$ & $118.4(2)$ & $117.95(15)$ & $117.93(15)$ \\
$\mathrm{Br} 13 \cdots \mathrm{Br} 15^{\mathrm{vi}}-\mathrm{C} 15^{\mathrm{vi}}$ & $156.1(2)$ & $155.94(17)$ & $156.24(16)$ \\
\hline & & &
\end{tabular}

Symmetry codes: (i) $-x+1, y+\frac{1}{2},-z+\frac{1}{2}$; (ii) $x-\frac{1}{2}, y, z+\frac{3}{2}$; (iii) $x, y, z+1$; (iv) $x+\frac{1}{4},-y+\frac{1}{4}$, $z-\frac{3}{4}$; (v) $x-\frac{1}{2},-y+\frac{1}{2},-z$; (vi) $-x+\frac{1}{2},-y+1, z-\frac{1}{2}$.

2020). The geometry optimizations and the calculations for $123 \mathrm{TBB}, 124 \mathrm{TBB}$ and $135 \mathrm{TBB}$ were performed using the Gaussian 09 program package (Frisch et al., 2009), along with the GaussView 5.0 graphical interface (Dennington et al., 2009). Density functional theory (DFT) calculations were carried out at the B3LYP/6-311-G(2d,2p) level of theory (Becke, 1988; Lee et al., 1988), in a vacuum, for the starting models of the isolated molecules adopted from the X-ray diffraction results.

\section{Results}

123TBB crystallizes in the monoclinic space group $P 2_{1} / c$, $124 \mathrm{TBB}$ in the orthorhombic space group Fdd2 and 135TBB in the orthorhombic space group $P 2_{1} 2_{1} 2_{1}$. There is one independent molecule in the asymmetric unit for $135 \mathrm{TBB}$, two for $123 \mathrm{TBB}$ and three for 124TBB. For these isomers, no transition or symmetry changes were detected from 270 to $100 \mathrm{~K}$. In this temperature range, the volume of the unit cells of the crystals similarly contract by 3.01 (123TBB), 2.67 (124TBB) and $3.04 \%$ (135TBB); their unit-cell parameters contract nearly linearly, but at different rates. The largest linear contraction of $1.49 \%$ is that of the shortest $a$ parameter in 135TBB (Table 1 and Tables S1-S3 in the supporting information).

The crystals of all the studied isomers, similar to other halogenated benzenes, can be considered as being built of layers composed of tribromobenzene molecules connected

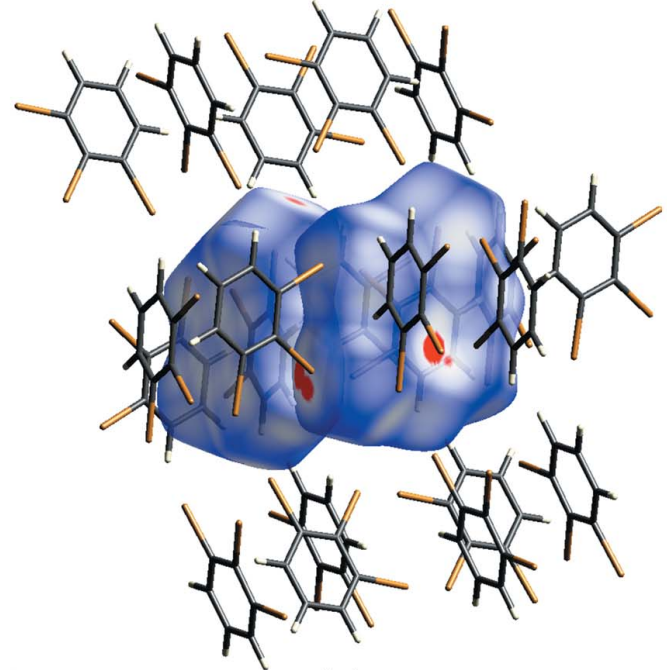

(a)

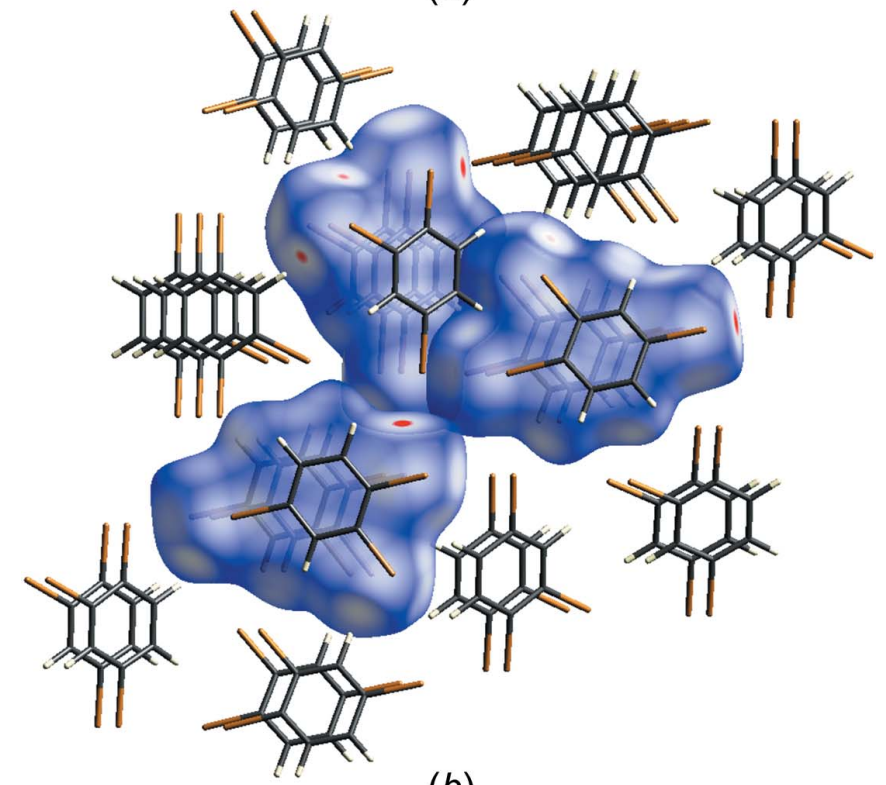

(b)

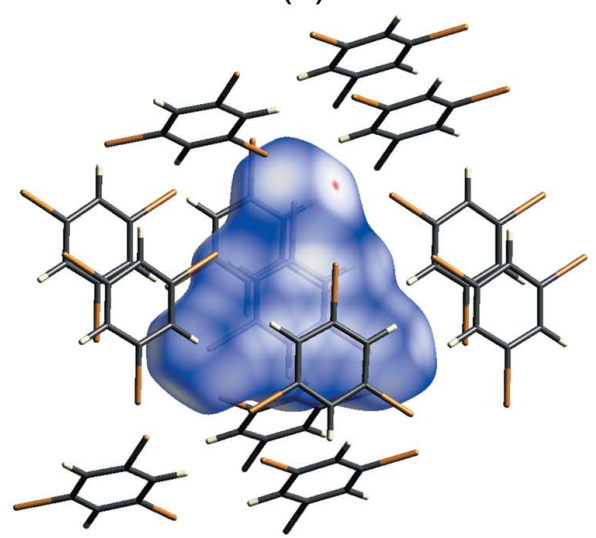

(c)

Figure 2

Hirshfeld surfaces (generated separately for symmetry-independent molecules) mapped with $d_{\text {norm }}(-0.02$ to 0.80$)$ and close molecules within a radius of $4.0 \AA$, at $100 \mathrm{~K}$, for $(a)$ two $123 \mathrm{TBB}$ molecules [C(11-16) left and $\mathrm{C}(21-26)$ right]; (b) three 124TBB molecules [C(11-16) upper, $\mathrm{C}(21-26)$ middle and $\mathrm{C}(31-36)$ bottom] and $(c)$ 135TBB. 
through $\mathrm{Br} \cdots \mathrm{Br} / \mathrm{C} / \mathrm{H}$ interactions (Figs. S1-S3 in the supporting information). At $100 \mathrm{~K}$, the distance between parallel aromatic rings is similar, ca $3.5 \AA$, in both $123 \mathrm{TBB}$ and $135 \mathrm{TBB}$, and it is ca $3.6 \AA$ in $124 \mathrm{TBB}$. The molecules of $123 \mathrm{TBB}, 124 \mathrm{TBB}$ and $135 \mathrm{TBB}$ are nearly planar as scrutinized in the supporting information.

The molecular dimensions of the studied tribromobenzenes show some steric hindrance between adjacent $\mathrm{Br}$ and $\mathrm{H}$ substituents in the aromatic rings. The shortest intramolecular distances of $\mathrm{Br} \cdots \mathrm{Br}=3.307(1) \AA, \mathrm{H} \cdots \mathrm{H}=2.30 \AA$ and $\mathrm{Br} \cdots \mathrm{H}=2.83 \AA$, which are clearly below the sums of the van der Waals radii (Bondi, 1964), are present in 123TBB and $124 \mathrm{TBB}$ at $270 \mathrm{~K}$.

Intermolecular contacts involving $\mathrm{Br}$ atoms are present in all isomers and their lengths decrease on cooling (Table 2 and Tables S7, S8 and S10). The largest contraction of

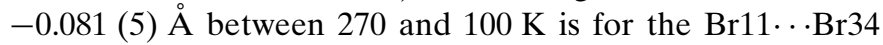
halogen bond in $124 \mathrm{TBB}$. Also, the $\mathrm{Br} \cdots \mathrm{H}$ contacts, in general, contract on cooling (Tables S8 and S9). Interestingly, according to the criterion of the sum of the van der Waals radii, at $270 \mathrm{~K}$, intermolecular $\mathrm{Br} \cdots \mathrm{Br}$ bonds are present only in $123 \mathrm{TBB}$ and $124 \mathrm{TBB}$, whereas the first $\mathrm{Br} \cdots \mathrm{Br}$ halogen bond in 135TBB appears in the structure at $c a 175 \mathrm{~K}$ (Tables 2 and S10). The intermolecular contacts for the structures of the isomers at $100 \mathrm{~K}$ are discussed below.

In $123 \mathrm{TBB}$, the intermolecular $\mathrm{Br} 11 \cdots \mathrm{Br} 12$ distance is 3.5850 (6) $\AA$. Atoms $\mathrm{Br} 13$ and $\mathrm{Br} 23$ are involved in $\mathrm{C} 13-\mathrm{Br} 13 \cdots \pi$ and $\mathrm{C} 23-\mathrm{Br} 23 \cdots \pi$ interactions (Pang et al., 2013; Wang et al., 2016; Mahadevi \& Sastry, 2016). The shortest Br..C separations are Br13..C23 of 3.393 (4) $\AA$ and $\mathrm{Br} 23 \cdots \mathrm{C} 13$ of $3.395(5) \AA$, whereas the corresponding $\mathrm{Br} \cdots \pi$ (centroid) distances are 3.392 (2) and 3.464 (2) $\AA$, respectively (Spek, 2020; Tables 2 and S7, and Fig. S4). The intermolecular interactions of the 124TBB molecules are different. According to the criterion of the van der Waals radii, none of the independent molecules form $\mathrm{C}-\mathrm{Br} \cdots \pi$ interactions, but only $\mathrm{Br} \cdots \mathrm{Br}$ and $\mathrm{Br} \cdots \mathrm{H}$ interactions. Molecule $\mathrm{C}(11-\mathrm{C} 16)$ is involved in six interactions, while molecules

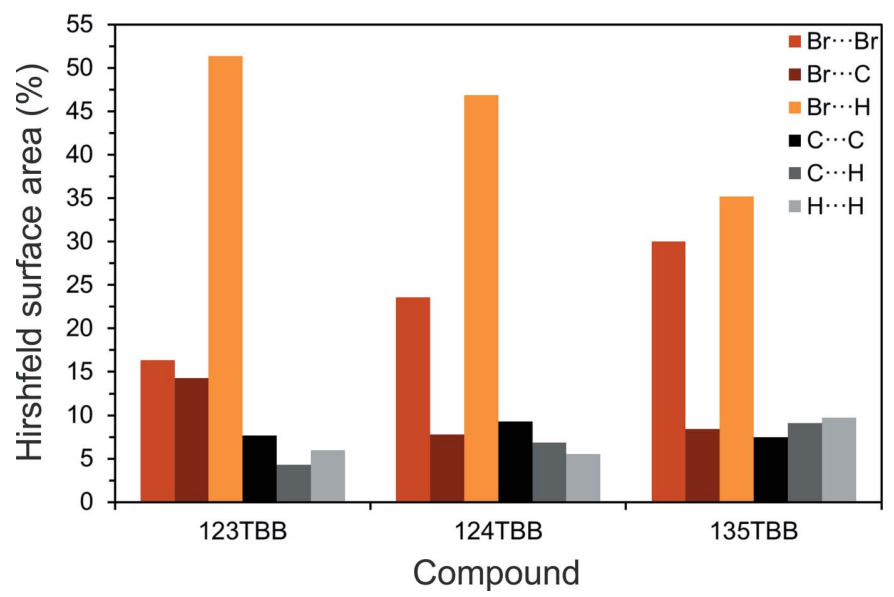

Figure 3

Distribution of contacts, at $100 \mathrm{~K}$, based on their area on the Hirshfeld surfaces for 123TBB, 124TBB and 135TBB (the averaged values for the independent molecules are presented, $c f$. Fig. S8).
$\mathrm{C}(21-26)$ and $\mathrm{C}(31-36)$ are involved in four halogen bonds each. The shortest $\mathrm{Br} \cdots \mathrm{Br}$ and $\mathrm{Br} \cdot \mathrm{H}$ distances are 3.565 (3) and $2.97 \AA$, respectively (Tables 2, S8 and S9, and Fig. S5). In $135 \mathrm{TBB}$, the Br13..B Br15 distance is 3.6994 (7) $\AA$ and atom Br13 is also engaged in two $\mathrm{Br} \cdots \mathrm{Br}$ bonds of 3.6724 (8) $\AA$, as well as in one $\mathrm{Br} 13 \cdots \pi$ interaction, characterized by $\mathrm{Br} \cdots \mathrm{C}$

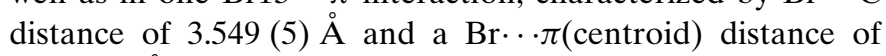
3.786 (2) A (Spek, 2020; Tables 2 and S10, and Fig. S6).

The contribution of specific types of interactions to the overall cohesion forces in the crystals can be estimated roughly by the number and interatomic distances of the intermolecular contacts for one molecule. According to this criterion, the largest contribution of the $\mathrm{Br} \cdots \mathrm{Br}$ bonds is in 135TBB. In this compound, the $\mathrm{Br}$ atoms are more exposed and better accessed compared to $123 \mathrm{TBB}$ and $124 \mathrm{TBB}$. At low temperature, due to crystal contraction, the distances become shorter, approximately at the same rate for all isomers.

The $\mathrm{Br} \cdots \mathrm{Br}$ halogen bonds formed in tribromobenzenes are somewhat distorted from idealized types I and II. In both $124 \mathrm{TBB}$ and $135 \mathrm{TBB}$, the $\mathrm{Br} \cdots \mathrm{Br}$ interactions, mainly of electrostatic type II, are relatively long. In contrast, the $123 \mathrm{TBB}$ crystal structure is governed by relatively short dispersion type I Br. B Br bonds (Desiraju \& Parthasarathy, 1989; Pedireddi et al., 1994; Awwadi et al., 2006; Fourmigué, 2009; Mukherjee et al., 2014; Cavallo et al., 2016).

The Hirshfeld surfaces and corresponding fingerprint plots illustrate the distribution of the types of cohesion forces in tribromobenzenes (Turner et al., 2017; McKinnon et al., 2004, 2007; Spackman \& Jayatilaka, 2009). This analysis covers a broad range of possible intermolecular contacts, also those longer than the sums of the van der Waals radii. Contacts shorter than the sums of the van der Waals radii, coloured red in Figs. 2 and S7, mainly relate to $\mathrm{Br} \cdots \mathrm{Br}, \mathrm{Br} \cdots \mathrm{C}(\mathrm{Br} \cdots \pi)$ and $\mathrm{Br} \cdots \mathrm{H}$. All the fingerprint plots contain the sharp central red regions representing $\mathrm{Br} \cdots \mathrm{Br}$ and two symmetrically located blue spikes for $\mathrm{Br} \cdot \mathrm{H}$ contacts. The blue regions close to the $\mathrm{Br} \cdots \mathrm{Br}$ red areas are due to $\mathrm{Br} \cdots \mathrm{C}(\mathrm{Br} \cdots \pi)$ contacts (Fig. S7c). The plot for molecule C(11-16) of 124TBB has a different distribution of $\mathrm{H} \cdot \cdots \mathrm{H}$ contacts (blue area between the $\mathrm{Br} \cdots \mathrm{H}$ spikes; Fig. S7b).

\section{Discussion}

Because in all the TBB isomers the high and low magnitudes of the calculated electrostatic potentials are associated with the $\mathrm{Br}$ atoms, one can expect that the electrostatic interactions mainly govern the aggregation of molecules. Fig. 3 shows the contribution of different contacts, assessed according to their portion on the Hirshfeld surfaces. The contacts involving $\mathrm{Br}$ atoms, i.e. $\mathrm{Br} \cdots \mathrm{Br}, \mathrm{Br} \cdots \mathrm{C}(\mathrm{Br} \cdots \pi)$ and $\mathrm{Br} \cdots \mathrm{H}$, constitute at least $c a 74 \%$ of all contacts in the three isomers. It appears from these statistics that the combined contacts of $\mathrm{Br} \cdots \mathrm{Br}$ and $\mathrm{Br} \cdots \mathrm{C}(\mathrm{Br} \cdots \pi)$ correlate with the highest melting point of $135 \mathrm{TBB}$; the sum of the $\mathrm{Br} \cdots \mathrm{Br}$ and $\mathrm{Br} \cdots \mathrm{C}(\mathrm{Br} \cdots \pi)$ contributions is ca 38 versus ca $31 \%$ for both $123 \mathrm{TBB}$ and $124 \mathrm{TBB}$. At the same time, the sum of the $\mathrm{Br} \cdots \mathrm{C}(\mathrm{Br} \cdots \pi)$ and $\mathrm{Br} \cdots \mathrm{H}$ contacts for $123 \mathrm{TBB}$ ( $\mathrm{ca} 66 \%$ ) is clearly higher than that for 
Table 3

Comparison of selected structural and thermodynamic parameters for 123TBB, 124TBB and 135TBB at $100 \mathrm{~K}$.

\begin{tabular}{llll}
\hline & $123 \mathrm{TBB}$ & $124 \mathrm{TBB}$ & $135 \mathrm{TBB}$ \\
\hline Space group & $P 2_{1} / c$ & $F d d 2$ & $P 2_{1} 2_{1} 2_{1}$ \\
$Z, Z^{\prime}$ & 8,2 & 48,3 & 4,1 \\
$V / Z$ & 188.03 & 188.8 & 189.16 \\
Density (calculated, $\left.\mathrm{g} \mathrm{cm}^{-3}\right)$ & 2.780 & 2.768 & 2.763 \\
Void volume $/ Z\left(\AA^{3}\right)$ & 16.2 & 10.3 & 7.4 \\
Void volume of $V(\%)$ & 8.6 & 5.4 & 3.9 \\
Molecular symmetry & $m m 2 ; C_{2 v}$ & $m ; C_{s}$ & $6 m 2 ; D_{3 h}$ \\
Boiling point $(\mathrm{K})$ & $556^{*}$ & 548 & 544 \\
Melting point $(\mathrm{K})$ & 361.0 & 317.7 & 396.0 \\
Enthalpy of melting $\left(\mathrm{kJ} \mathrm{mol}^{-1}\right)$ & Not available & 17.9 & 21.7 \\
Entropy of melting $\left(\mathrm{J} \mathrm{K}^{-1} \mathrm{~mol}^{-1}\right)$ & Not available & $56^{* *}$ & $55^{* *}$ \\
\hline
\end{tabular}

Notes and references: $(*)$ Nakada et al. (1970); (**) entropy of melting calculated from the enthalpy of melting (Kuramochi et al., 2004; van der Linde et al., 2005) and the melting point (Mackay et al., 2006).

the less symmetric isomer 124TBB ( $c$ a 55\%), having the lowest melting point.

Neither the variances in the contribution of specific types of contacts at different temperatures nor those for independent molecules significantly affect the above-mentioned analysis (Fig. S8). Furthermore, as mentioned previously, the $\mathrm{Br} \cdots \mathrm{Br}$ halogen bonds in both $135 \mathrm{TBB}$ and $124 \mathrm{TBB}$ are of distorted type II, whereas those in $123 \mathrm{TBB}$ are of distorted type I. Also, the shortest $\mathrm{Br} \cdots \mathrm{H}$ bonds, found in $124 \mathrm{TBB}$ only, are of both distorted type I and II interactions. This shows that both the nature and distribution of specific cohesion forces may contribute to the differentiation of the melting points of isomeric tribromobenzenes.

The magnitudes of the calculated molecular electrostatic potential are correlated with the preferences of particular atoms to form intermolecular interactions (Cavallo et al., 2016; Fig. S9). The electrostatic potential on the $\mathrm{Br}$ atoms in $135 \mathrm{TBB}$ is equally distributed, which favours electrostatic type II halogen bonds evenly distributed in space, because $\mathrm{Br}$ atoms are easily accessed for intermolecular interactions.

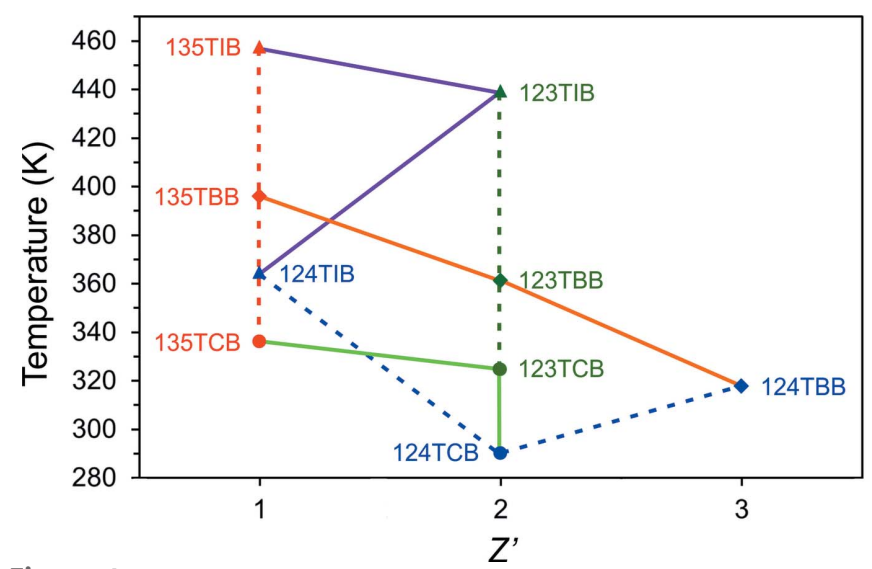

Figure 4

Melting points for series of isomers: $(\bullet)$ trichloro- $(\mathrm{TCB}),(\bullet)$ tribromo(TBB) and ( $\triangle$ ) triiodobenzenes (TIB), plotted as a function of $Z^{\prime}$. The solid lines join the points for isomers containing the same halogen atoms, while the dashed lines are for isomers with the same halogen-atom positions in an aromatic ring. Both the solid and dashed lines are guides for the eye only.
From a thermodynamic point of view, melting is a process that depends on the balance between the enthalpy and entropy of melting. The enthalpy component is associated mainly with molecular size and intermolecular interactions, whereas entropy, related to molecular symmetry and flexibility, affects the arrangement and packing of molecules (Yalkowsky \& Alantary, 2018). Therefore, the high symmetry of molecules facilitates their interactions and crystal formation, which results in a lower entropy of melting and in a higher melting point.

The selected structural and thermodynamic parameters for the tribromobenzene isomers are collected in Table 3. The unit-cell volume per molecule $(V / Z)$ and the calculated density parameters are comparable for all the studied isomers. The void volume $/ Z$ and the relative volume of voids gradually decreases from $123 \mathrm{TBB}$ to $124 \mathrm{TBB}$ and are lowest for 135TBB (Figs. S1-S3). It appears that the melting point for tribromobenzenes decreases with an increasing number of molecules in the asymmetric unit $\left(Z^{\prime}\right)$; however, this regularity does not apply to the 124TIB and 124TCB isomers (Fig. 4). It is intriguing that in this series of isomers, the least dense $135 \mathrm{TBB}$ has the highest melting point, which is inconsistent with the observation that more dense crystals usually have higher melting points.

The tribromobenzene isomers are composed of ordered rigid molecules; thus, the differences in their melting points, like those of disubstituted benzenes (Gavezzotti, 1995; Bujak et al., 2007; Dziubek \& Katrusiak, 2014), can be associated with the enthalpy-related components, such as cohesion forces. This further confirms the arguments based on the analysis of the nature and distribution of intermolecular interactions.

\section{Conclusions}

The crystals of three tribromobenzene isomers have been investigated at low temperature in order to explore the relationships between the intermolecular interactions and melting points of these compounds. Beside the symmetry, described by Carnelley's rule, the intuitive principle for the melting-point differences can be associated with cohesion forces: the stronger and more frequent the interactions between molecules the more energy is required to melt the crystal. The present results show that the strongest halogen bonds alone cannot account for the melting-point differences. Therefore weaker intermolecular interactions have to be considered too. Higher molecular symmetry provides better access to the $\mathrm{Br}$ atoms and hence the specific optimum interactions that correlate with the higher melting point of the particular isomer.

\section{References}

Awwadi, F. F., Willett, R. D., Peterson, K. A. \& Twamley, B. (2006). Chem. Eur. J. 12, 8952-8960.

Beacall, T. (1928). Recl Trav. Chim. Pays Bas, 47, 37-44.

Becke, A. D. (1988). Phys. Rev. A, 38, 3098-3100. 
Belaaraj, A., Nguyen-ba-Chanh, Haget, Y. \& Cuevas-Diarte, M. A. (1984). J. Appl. Cryst. 17, 211.

Boese, R., Weiss, H.-C. \& Bläser, D. (1999). Angew. Chem. Int. Ed. 38, 988-992.

Bondi, A. (1964). J. Phys. Chem. 68, 441-451.

Brown, R. J. C. \& Brown, R. F. C. (2000). J. Chem. Educ. 77, 724-731.

Bujak, M. (2018). Acta Cryst. B74, 458-466.

Bujak, M., Dziubek, K. \& Katrusiak, A. (2007). Acta Cryst. B63, 124131.

Bujak, M., Podsiadło, M. \& Katrusiak, A. (2008). J. Phys. Chem. B, 112, 1184-1188.

Carnelley, T. (1882). London, Edinb. Dubl. Philos. Mag. J. Sci. 13, 112-130.

Cavallo, G., Metrangolo, P., Milani, R., Pilati, T., Priimagi, A., Resnati, G. \& Terraneo, G. (2016). Chem. Rev. 116, 2478-2601.

Dennington, R., Keith, T. \& Millam, J. (2009). GaussView 5.0. Semichem Inc., Shawnee Mission, KS, USA.

Desiraju, G. R. \& Parthasarathy, R. (1989). J. Am. Chem. Soc. 111, 8725-8726.

Dziubek, K. F. \& Katrusiak, A. (2014). Acta Cryst. B70, 492-497.

Fourmigué, M. (2009). Curr. Opin. Solid State Mater. Sci. 13, 36-45.

Frisch, M. J., Trucks, G. W., Schlegel, H. B., Scuseria, G. E., Robb, M. A., Cheeseman, J. R., Scalmani, G., Barone, V., Mennucci, B., Petersson, G. A., Nakatsuji, H., Caricato, M., Li, X., Hratchian, H. P., Izmaylov, A. F., Bloino, J., Zheng, G., Sonnenberg, J. L., Hada, M., Ehara, M., Toyota, K., Fukuda, R., Hasegawa, J., Ishida, M., Nakajima, T., Honda, Y., Kitao, O., Nakai, H., Vreven, T., Montgomery, J. A. Jr, Peralta, J. E., Ogliaro, F., Bearpark, M., Heyd, J. J., Brothers, E., Kudin, K. N., Staroverov, V. N., Kobayashi, R., Normand, J., Raghavachari, K., Rendell, A., Burant, J. C., Iyengar, S. S., Tomasi, J., Cossi, M., Rega, N., Millam, J. M., Klene, M., Knox, J. E., Cross, J. B., Bakken, V., Adamo, C., Jaramillo, J., Gomperts, R., Stratmann, R. E., Yazyev, O., Austin, A. J., Cammi, R., Pomelli, C., Ochterski, J. W., Martin, R. L., Morokuma, K., Zakrzewski, V. G., Voth, G. A., Salvador, P., Dannenberg, J. J., Dapprich, S., Daniels, A. D., Farkas, O., Foresman, J. B., Ortiz, J. V., Cioslowski, J. \& Fox, D. J. (2009). Gaussian 09. Revision A.02. Gaussian Inc., Wallingford CT, USA. https://gaussian.com.

Gallagher, J. F., Farrell, M., Hehir, N., Mocilac, P., Aubert, E., Espinosa, E., Guillot, B. \& Jelsch, C. (2019). Cryst. Growth Des. 19, 6141-6158.

Gavezzotti, A. (1995). J. Chem. Soc. Perkin Trans. 2, pp. 1399-1404. Holler, A. C. (1948). J. Org. Chem. 13, 70-74.

Joseph, S., Sathishkumar, R., Mahapatra, S. \& Desiraju, G. R. (2011). Acta Cryst. B67, 525-534.

Katritzky, A. R., Jain, R., Lomaka, A., Petrukhin, R., Maran, U. \& Karelson, M. (2001). Cryst. Growth Des. 1, 261-265.

Kuramochi, H., Maeda, K. \& Kawamoto, K. (2004). J. Chem. Eng. Data, 49, 720-724.
Lee, C., Yang, W. \& Parr, R. G. (1988). Phys. Rev. B, 37, 785-789.

Linde, P. R. van der, van Miltenburg, J. C., van den Berg, G. J. K. \& Oonk, H. A. J. (2005). J. Chem. Eng. Data, 50, 164-172.

Mackay, D., Shiu, W. Y., Ma, K.-C. \& Lee, S. C. (2006). Handbook of Physical-Chemical Properties and Environmental Fate for Organic Chemicals, 2nd ed. Boca Raton, FL: CRC Press.

Macrae, C. F., Sovago, I., Cottrell, S. J., Galek, P. T. A., McCabe, P., Pidcock, E., Platings, M., Shields, G. P., Stevens, J. S., Towler, M. \& Wood, P. A. (2020). J. Appl. Cryst. 53, 226-235.

Mahadevi, A. S. \& Sastry, G. N. (2016). Chem. Rev. 116, 2775-2825.

McKinnon, J. J., Jayatilaka, D. \& Spackman, M. A. (2007). Chem. Commun. pp. 3814-3816.

McKinnon, J. J., Spackman, M. A. \& Mitchell, A. S. (2004). Acta Cryst. B60, 627-668.

Milledge, H. J. \& Pant, L. M. (1960). Acta Cryst. 13, 285-290.

Mukherjee, A., Tothadi, S. \& Desiraju, G. R. (2014). Acc. Chem. Res. 47, 2514-2524.

Nakada, M., Fukushi, S., Tomita, H. \& Mashiko, Y. (1970). Kogyo Kagaku Zasshi, 73, 929-932.

Pang, X., Wang, H., Zhao, X. R. \& Jin, W. J. (2013). CrystEngComm, 15, 2722-2730.

Pedireddi, V. R., Reddy, D. S., Goud, B. S., Craig, D. C., Rae, A. D. \& Desiraju, G. R. (1994). J. Chem. Soc. Perkin Trans. 2, pp. 23532360.

Podsiadło, M., Bujak, M. \& Katrusiak, A. (2012). CrystEngComm, 14, 4496-4500.

Podsiadło, M., Olejniczak, A. \& Katrusiak, A. (2013). J. Phys. Chem. C, 117, 4759-4763.

Rigaku Oxford Diffraction (2018). CrysAlisPro. Rigaku Corporation, The Woodlands, TX, USA.

Sheldrick, G. M. (2008). Acta Cryst. A64, 112-122.

Sheldrick, G. M. (2015). Acta Cryst. C71, 3-8.

Spackman, M. A. \& Jayatilaka, D. (2009). CrystEngComm, 11, 19-32.

Spek, A. L. (2020). Acta Cryst. E76, 1-11.

Thalladi, V. R. \& Boese, R. (2000). New J. Chem. 24, 579-581.

Thalladi, V. R., Boese, R. \& Weiss, H.-C. (2000a). Angew. Chem. Int. Ed. 39, 918-922.

Thalladi, V. R., Boese, R. \& Weiss, H.-C. (2000b). J. Am. Chem. Soc. 122, 1186-1190.

Thalladi, V. R., Nüsse, M. \& Boese, R. (2000c). J. Am. Chem. Soc. 122, 9227-9236.

Turner, M. J., McKinnon, J. J., Wolff, S. K., Grimwood, D. J., Spackman, P. R., Jayatalika, D. \& Spackman, M. A. (2017). CrystalExplorer17. University of Western Australia, Australia. http://hirshfeldsurface.net.

Wang, H., Wang, W. \& Jin, W. J. (2016). Chem. Rev. 116, 5072-5104. Yalkowsky, S. H. \& Alantary, D. (2018). J. Pharm. Sci. 107, 1211-1227. 